\title{
Tampilan Nama Hari Berbasis Mikrokontroler Arduino Uno Menggunakan Saklar Tekan pada Project Board
}

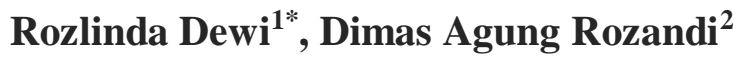 \\ ${ }^{1,2}$ Teknik Elektro, Fakultas Teknik, Universitas Batanghari \\ *Correspondence Email: rozlinda.dewi@unbari.co.id; agung.rozandi@gmail.com
}

\begin{abstract}
Abstrak. Arduino Uno adalah salah satu varian dari produk board mikrokontroller keluaran Arduino. Arduino Uno menggunakan mikrokontroller AVR Atmega 328. Di dalam menampilkan (Display) nama hari yang menggunakan teknologi mikrokontroler Arduino Uno biasanya langsung terprogram. Namun terkadang didalam perancangan alat mengalami eror pada saat upload program Integrated development Environment (IDE) Arduino, maka dari itu digunakan tombol saklar tekan (Push Button) untuk mengedit tampilan nama hari. Untuk itu penelitian ini menggunakan saklar tekan (Push Button) dalam mengatasi eror tersebut. rancang bangun tampilan nama hari ini adalah dapat Menggunakan saklar tekan untuk memudahkan ketika ingin mengedit tampilan nama hari tanpa menggunakan bahasa pemrograman Arduino IDE dan laptop. Kesalahan (eror) pada saklar tekan tidak berfungsi adalah terletak pada kaki kabel jumper yang longgar atau kaki pada kabel jumper patah.
\end{abstract}

Kata Kunci: Mikrokontroler Arduino Uno; Saklar Tekan; Project Board

Abstract. Arduino Uno is a variant of Arduino microcontroller board products. Arduino Uno uses AVR Atmega 328 microcontroller. With various advantages, In appearance (Display) the name of the day using Arduino Uno microcontroller technology is usually directly programmed. But sometimes the design of tools is moved when uploading the Arduino integrated development environment (IDE) program, therefore a push button (push button) is used to change the appearance of the day's name. For this study using a push switch (Push Button) in overcoming the error.

Keywords: Arduino Uno Microcontroller; Push Switch; Project Board

\section{PENDAHULUAN}

Teknologi mikrokontroler saat ini maju dengan sangat cepat, hampir seluruh peralatan elektronika dikendalikan dengan mikrokontroler salah satu mikrokontroler yang banyak digunakan saat ini yaitu mikrokontroler Advanced Versatile RISC (AVR)

"AVR adalah mikrokontroler RISC (Reduce Instruction Set Compute) 8 bit berdasarkan arsitektur Harvard, yang dibuat oleh Atmel pada tahun 1996".

AVR memiliki keunggulan dibandingkan dengan mikrokontroler lain, yaitu memiliki kecepatan eksekusi program yang lebih cepat karena sebagian besar instruksi dieksekusi dalam satu clock. selain itu mikrokontroler AVR memiliki fitur yang lengkap (ADC internal, EEPROM Internal, Timer/Counter, PWM, Watchdog Timer, Port I/O, komunikasi serial, dll).

Arduino Uno adalah salah satu varian dari produk board mikrokontroller keluaran Arduino. Arduino Uno adalah board kecil yang menggunakan mikrokontroller AVR Atmega 328. Dengan berbagai kelebihan yang dimiliki. maka mikrokontroler AVR sangat cocok untuk diterapkan pada sistem kendali otomatis.

\section{Kelebihan Arduino}

1. Open Source

2. Tidak Menggunakan Chip Programer

3. Koneksi USB
4. Fasilitas Chip Yang Cukup Lengkap

5. Ukuran Kecil Dan Mudah Dibawa

6. Bahasa Pemrograman Relatif Mudah

7. Tersedia Library Gratis

8. Pengembangan Aplikasi Lebih Mudah

\section{Kelemahan Arduino}

1. Kode hex relatif lebih besar.

2. Sering terjadi kesalahan fuse bit pada saat membuat bootloader

3. Harus memodifikasi program lama, karena pada arduino penggunaan pin harus "Disiplin"

Selain menggunakan program, untuk mengedit tampilan hari dapat menggunakan saklar tekan (Push Button). Saklar tekan berfungsi sebagai pemutus atau penyambung arus listrik dari sumber arus menuju beban listrik. Saklar tekan memiliki kontak NC (Normally Close) dan NO (Normally Open).

Mikrokontroler adalah suatu rangkaian terintegrasi (IC) yang bekerja untuk aplikasi pengendali. Fungsi pengendali mikrokontroler memiliki beberapa bagian seperti Central Processing Unit (CPU), Read Only Memory (ROM), Random Access Memory (RAM), dan Unit I/O. arduino adalah pengendali mikrokontroler single-board yang bersifat opensource, turunan dari wiring platform, dan dirancang untuk mempermudah pengguna elektronik berbagai bidang. Hardware-nya memiliki prosesor AtmelAVR dan software-nya memiliki 
bahasa pemrograman sendiri yang memiliki kemiripan Syntax dengan Bahasa Pemrograman C.

Arduino menggunakan mikrokontroler yang dirilis oleh Atmel, beberapa individu atau perusahaan membuat clone-arduino menggunakan mikrokontroler lain namun tetap kompatibel dengan Arduino pada level hardware. Untuk fleksibilitas, program dimasukkan melalui bootloader yang terdapat opsi untuk mem-bypass bootloader dan menggunakan downloader untuk memprogram mikrokontroler secara langsung melalui port ISP.

Rumusan masalah adalah bagaimana cara mengaktifkan saklar tekan untuk mengedit tampilan hari pada mikrokontroler Arduino Uno Sedangkan batasan masalah adalah menguji tombol push button untuk display tampilan nama hari pada panel LED P10.

Tabel 1. Parameter Uji Tampilan Nama Hari menggunakan Saklar Tekan

\begin{tabular}{llccc}
\hline $\begin{array}{c}\text { Item Uji } \\
\text { Nama Hari }\end{array}$ & $\begin{array}{c}\text { Nama } \\
\text { Program }\end{array}$ & $\begin{array}{c}\text { Hari } \\
\text { Display }\end{array}$ & $\begin{array}{c}\text { Hasil } \\
\text { Sukses }\end{array}$ & $\begin{array}{c}\text { Uji } \\
\text { Tidak }\end{array}$ \\
\hline Senin & Sukses & Senin & Sukses & - \\
Selasa & Sukses & Selasa & Sukses & - \\
Rabu & Sukses & Rabu & Sukses & - \\
Kamis & Sukses & Kamis & Sukses & - \\
Jumat & Sukses & Jumat & Sukses & - \\
Sabtu & Sukses & Sabtu & Sukses & - \\
Ahad & Sukses & Ahad & Sukses & - \\
\hline
\end{tabular}

\section{Program Uji Tampilan Nama Hari}

if (kasus = 4) $\{$ //kasus seting hari dmd.clearScreen(true); dmd.selectFont(SystemFont5x7); dmd.drawString $(0,0$, "Hari", 4, 0); String xjam = Konversi(harin_e) if (harin_e $==0$ ) $\{$ xjam = "SEN"; int pjg $=$ xjam.length ()$+1 ;$ char $\operatorname{sjam[pjg];~}$ xjam.toCharArray(sjam, pjg); dmd.drawString $(0, \quad 9$, sjam, pjg, 0); $\}$ if (harin_e ==1) \{xjam = "SEL"; int pjg $=$ xjam.length ()$+1 ;$ char sjam[pjg]; xjam.toCharArray(sjam, pjg); dmd.drawString $(0,9$, sjam, pjg, 0); $\}$ if (harin_e == 2) \{xjam = "RAB"; int pjg $=$ xjam.length ()$+1 ; \quad$ char sjam[pjg]; xjam.toCharArray(sjam, pjg); dmd.drawString $(0,9$, sjam, pjg, 0); $\}$ if (harin_e $==3$ ) \{

\section{Gambar Rangkaian Saklar Tekan Hub}

To Arduino Hubung to Power suply

Hub to Panel LED P10

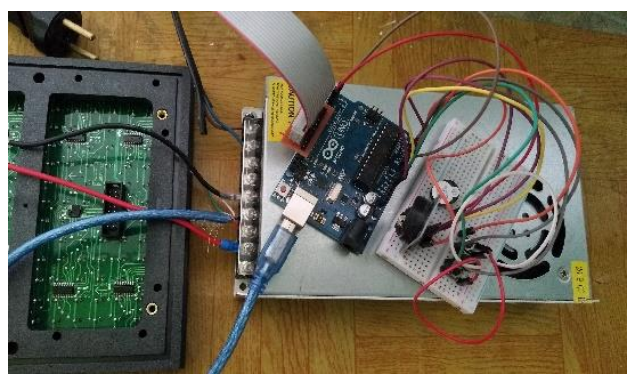

Gambar 1. Rangkaian Saklar Tekan Hub xjam $=$ "KAM"; int pjg $=$ xjam.length ()$+1$; char sjam[pjg]; $\quad$ xjam.toCharArray(sjam, $\quad$ pjg); dmd.drawString $(0,9$, sjam, pjg, 0$)$; $\}$ if (harin_e == 4) $\{$ xjam $=$ "JUM"; int pjg = xjam.length ()$+1$; char sjam[pjg]; $\quad$ xjam.toCharArray(sjam, $\quad$ pjg); dmd.drawString $(0,9$, sjam, pjg, 0); \} if (harin_e $==5$ ) $\{$ xjam $=$ "SAB"; int pjg = xjam.length ()$+1$; char sjam[pjg]; $\quad$ xjam.toCharArray(sjam, pjg); dmd.drawString $(0,9$, sjam, pjg, 0$)$; $\}$ if (harin_e == 6) $\{$ xjam $=$ "MIN"; int pjg = xjam.length ()$+1$; char sjam[pjg]; $\quad$ xjam.toCharArray(sjam, $\quad$ pjg); dmd.drawString $(0,9$, sjam, pjg, 0$) ;\}$

\section{Keterangan:}

1. Saklar Tekan sebagai mengaktivkan edit mode tampilan hari

2. Arduino Sebagai Mikrokontroler untuk membaca program input output dari saklar tekan

3. Power suply sebagai Pemberi tegangan serta arus listrik kepada komponen Panel Led P10 dan Mikrokontroler Arduino

4. Panel LED P10 untuk menampilkan tampilan nama hari

5. Kabel Jumper sebagai kabel hubung dari pin kaki saklar tekan menuju pin kaki Arduino

\section{METODE}

\section{Blok diagram}

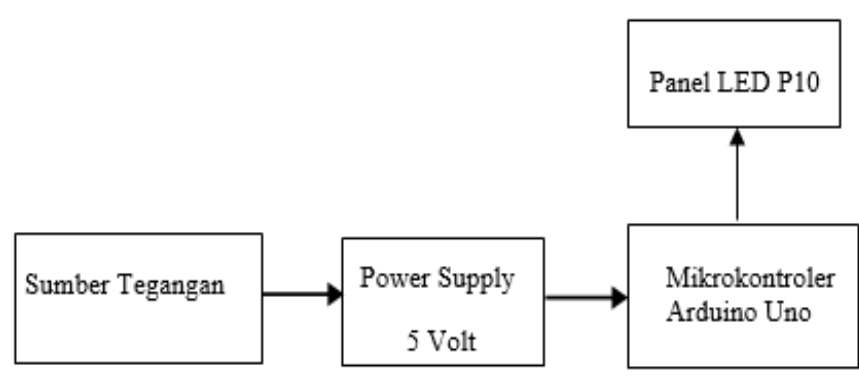

Gambar 2. Blok diagram sistem

1. Sumber Tegangan 220 volt sebagai masukan input menuju power suply 5 volt

2. Power suply 5 volt sebagai input masukan untuk mikrokontroler arduino uno, dan panel led P10

3. LED P10 sebagai monitoring kegiatan seperti jam, tanggal, dan karakter kata. LED ini terhubung dengan port usb pada mikrokontroler Arduino Uno.

4. Mikrokontroler Arduino Uno digunakan sebagai alat kendali seluruh kinerja dari LED Display P10 berbasis RTC DS 3231.

\section{Perangkat Hardware}

Komponen rangkaian harus dapat bekerja sesuai sistem yang diperintahkan oleh software pembuatan software harus sesuai dengan urutan perintah agar terjadi kesinambungan antara software dan hardware 


\section{Alat dan Bahan}

1. Arduino Uno

2. Kabel Jumper

3. Kabel USB

4. Panel LED P10

5. RTC DS 3231

6. Power Supply 5 Volt 40 ampere

7. Push Button

8. Project Board

\section{Perancangan Software}

Perancangan perangkat lunak (Software) dilakukan dengan menentukan langkah kerja yang digambarkan dengan diagram alir (Flowchart). Hal ini dimaksudkan agar memperoleh langkah-langkah yang efektif dan efisiensi. Langkah selanjutnya direalisasikan ke dalam program Integrated Development Environment (IDE) yang kemudian di teruskan ke Panel LED P10.

Perancangan tampilan nama hari pada panel LED P10 sholat berbasis mikrokontroler Arduino Uno dengan RTC DS 3231. Program ini menggunakan Software Integrated Development Environment (IDE) Arduino.

\section{Langkah Uji}

1. Hubungkan masing-masing kaki board Arduino Uno (GND, A1, A2, A3) ke kaki Saklar Tekan $(1,2,3)$

2. Buka IDE Arduino kemudian ketik kode program/sketch tampilan nama hari

3. Upload program ke arduino dengan cara, file > Upload to I/O board, atau tekan tombol tanda panah pada jendela IDE Arduino.

4. Ketika sudah di upload, untuk mengaktivkan atau mengedit tampilan nama hari tekan tombol saklar tekan yang di tengah selama 5-10 detik untuk memasuki edit mode

5. Tombol saklar tekan kiri untuk mengganti ke hari sebelumnya

6. Tombol saklar tekan kanan untuk mengganti ke hari selanjutnya

\section{HASIL DAN PEMBAHASAN}

Tabel 2. Hasil Tampilan Nama Hari

\begin{tabular}{ccc}
\hline $\begin{array}{c}\text { Uji Tampilan } \\
\text { nama hari }\end{array}$ & Display nama hari & Sukses \\
\hline Senin & & Sukses \\
& \\
& & \\
&
\end{tabular}

Selasa

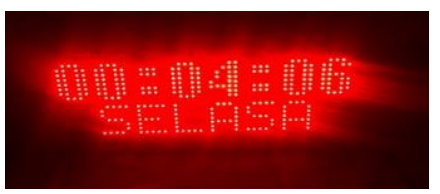

Rabu

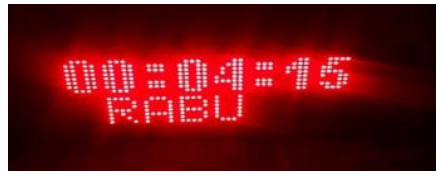

Sukses

Kamis

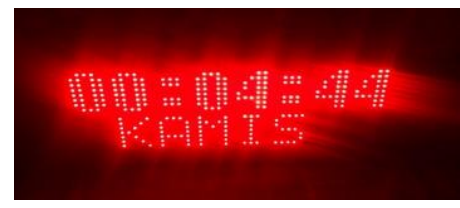

Sukses

Jum'at

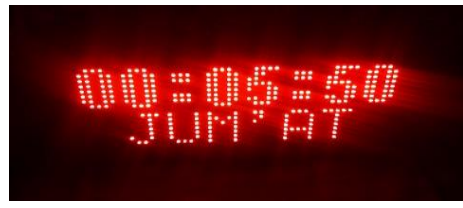

Sukses

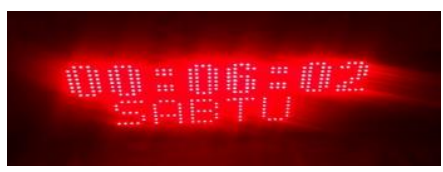

Sukses

Sabtu

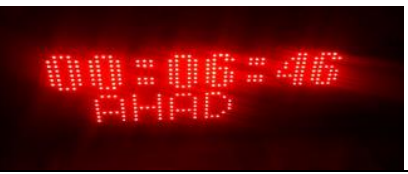

Sukses

Ahad

\section{Pembahasan}

1. Pembahasan dari hasil yang dilakukan, Tampilan nama hari akan berubah dengan skala waktu $1 \times 24$ jam

2. Cara kerja saklar tekan untuk mengedit tampilan nama hari adalah, dengan menggunakan saklar tekan yg terdapat 3 buah saklar tekan pada papan project board. Saklar tekan akan dapat berfungsi apabila kaki jumper pada pada saklar tekan masing-masing telah di jumper ke Arduino dengan baik dan benar

3. Dengan menggunakan RTC DS 3231 perubahan tampilan nama hari secara otomatis akan berubah tanpa perlu merubahnya pada program IDE Arduino

\section{SIMPULAN}

1. Saklar tekan berfungsi mengedit tampilan nama hari

2. Perangkat lunak atau software arduino uno yang digunakan adalah Integrated Development Environment(IDE)

3. Uji Tampilan Nama Hari sukses sesuai dengan item uji yang ditentukan

4. Cara kerja Mikrokontroler mengaktifkan tombol Saklar tekan untuk menampilkan tampilan nama Hari

5. Ada 3 saklar tekan pada papan project board yang memiliki fungsi berbeda

6. Fungsi saklar tekan kiri untuk tampilan hari sebelumnya, saklar tekan kanan untuk tampilan nama hari berikutnya, dan saklar tekan tengah untuk memasuki menu edit mode 


\section{DAFTAR PUSTAKA}

[1] Muhammad ID, Mintarsih F. Penentuan Waktu Sholat dan menampilkan nama hari, p-ISSN 19790767 (1) :-10 (2013).

[2] Riyadi S. Mengedit tampilan waktu sholat dan nama hari. Yogyakarta : Andi Offset : 1-4 (2011).

[3] Santoso, H. Panduan Praktis Arduino untuk Pemula. Ebook Versi 1 (2015).

[4] Wahyu Aulia Nurwicaksana dkk, ALAT PENGINGAT WAKTU SHOLAT DI MASJID BERBASIS RASBERRY PI, Prosiding SNATIV Ke4 Politeknik Negeri Malang (2017).

[5] Sudjadi, darmawan and Darjat, "Rancang Bangun Jam Digital Waktu Sholat Berbasis Mikrokontroler At89S52," Transient (2013).

[6] S.R. Anton Yudhana, Abdul Fadilil, "Rancang Bangun Jadwal Sholat Digital Terkendali Android," Semantikom (2017). 